\title{
NILAI KESANTUNAN DALAM MANTRA MEOLI
}

\author{
(Politeness Value in Meoli Spell)
}

\author{
Heksa Biopsi Puji Hastuti \\ Kantor Bahasa Sulawesi Tenggara \\ Kompleks Bumi Praja, Jalan Haluoleo, Anduonohu, Kendari, Indonesia \\ Pos-el: heksa.bph@gmail.com
}

\begin{abstract}
Abstrak: Mantra meoli hadir sebagai satu paket pentas dalam kemasan ritual adat, yaitu ritual meoli. Ritual meoli merupakan ekspresi kesantunan pelakunya dalam mengutarakan maksud permintaan izin atau permintaan maaf kepada para sangia sebagai penguasa alam, ketika membuka lahan untuk bercocok tanam. Penelitian ini mengkaji nilai kesantunan dalam mantra meoli dengan pendekatan etnopuitika. Permasalahan yang diangkat yaitu bagaimana nilai kesantunan termuat dalam mantra meoli. Dengan menerapkan metode penelitian kualitatif, pengumpulan data dilakukan dengan teknik observasi, wawancara, dan studi pustaka. Dari hasil analisis diketahui bahwa nilai kesantunan dalam mantra meoli mewujud skala prioritas di mana yang diutamakan adalah penjunjungan adat, diikuti dengan permohonan maaf dengan menyebutkan seluruh sangia yang dituju, baru dipungkasi dengan pengutaraan maksud dan harapan sebagai inti pesan dari mantra meoli. Cara pengungkapan yang indah juga mendukung nilai kesantunan dalam mantra meoli.
\end{abstract}

Kata Kunci: nilai kesantunan, mantra meoli, Moronene

Abstract: Meoli spell present as one performance package within custom ritual called meoli ritual. Meoli ritual is a politeness expression of the perpetrators in expressing the purpose of request permission or apology to the sangia as the ruler of nature when opening the land to grow crops. This study examines the value of politeness in the meoli spell with the ethnopoetic approach. The issues raised are how is the politeness value existed in the meoli spell. By applying qualitative research method, data collection is done by observation, interview, and literature study. From the analysis, it is known that the value of politeness in the meoli mantra embodies the priority scale in which the preferred is the custom observer, followed by an apology by mentioning the whole of the target, newly expressed by the expression of intent and hope as the core message of the meoli spell. The beautiful way of disclosure also supports the value of politeness in the meoli spell.

Keywords: politeness value, meoli spells, Moronene

\section{PENDAHULUAN}

Suku Moronene, salah satu suku yang mendiami wilayah daratan Sulawesi Tenggara, sampai saat ini masih akrab dengan mantra. Mantra menjadi kekayaan sastra lisan suku Moronene yang berbentuk puisi selain ohoohi, ohooho, doede, dan dulele (Hastuti, dkk., 2016, hlm. 70-75). Mantra mengisi ruang kehidupan masyarakat Moronene bebarengan dengan masih terpeliharanya pelaksanaan beberapa ritual adat. Suku Moronene yang pada beberapa wilayah terkonsentrasi secara homogen, atau nyaris homogen, membentuk pemukiman adat. Pemukiman adat ini misalnya dapat dijumpai di Hukaea-Laeya, di mana sembilan puluh persen penduduknya adalah suku Moronene. Masyarakat di sana masih mempertahankan sistem dan pranata sosial lokal secara institusional. Hal ini salah satunya teraca dari melembaganya praktik kearifan dan pengetahuan lokal dari leluhur mereka, misalnya pengurusan sumberdaya alam (Muis, 2010). Sistem dan pranata 
sosial yang melembaga ini mengemban berbagai fungsi dalam masyarakat Moronene. Selain sebagai pedoman berperilaku, sistem dan pranata sosial Moronene juga berfungsi sebagai hukum tidak tertulis dan alat kontrol sosial (Limba, dkk., 2015, hlm. 43).

Tulisan ini berasal dari penelitian mandiri penulis yang dilakukan pada tahun 2014. Dalam penelitian awal tersebut diperoleh deskripsi aspek verbal dan nonverbal ritual meoli ${ }^{1}$. Aspek verbal ritual tersebut hadir dalam wujud mantra yang diucapkan dalam salah satu pranata sosial masyarakat Moronene yang masih lestari ini. Dalam publikasi ini dilakukan pengkajian lebih lanjut mengenai bagaimana nilai kesantunan suku Moronene di Hukaea-Laeya dikatakan hadir melalui mantra meoli.

Terkait penulisan, dalam beberapa publikasi istilah meoli ditulis mooli atau mo'ooli (Hastuti, 2015; dan Limba, 2016 menuliskannya mo'oli; Muis, 2010 menuliskannya mooli). Perbedaan penulisan istilah dalam bahasa daerah Moronene ini terjadi karena ada perbedaan pengucapan di beberapa daerah dan belum adanya pembakuan tata penulisannya. Hal ini dibenarkan oleh Jumrad Raunde, Ketua Dewan AMAN (Aliansi Masyarakat Adat Nusantara) Kabupaten Bombana. Menurut Raunde, penggunaan kata mo'oli atau mo'ooli digunakan untuk kepentingan sesame manusia. Sementara itu, kata meoli adalah kata adat yang digunakan saat seseorang berhajat kepada hal gaib. Secara konsep, meoli adalah suatu hajat yang dilakukan atau disampaikan kepada roh untuk melindungi, menjaga, dan atau menyukseskan apa yang menjadi keinginan dari masyarakat di tempat itu.

Secara denotatif, meoli, mo'oli, atau mo'ooli merujuk pada makna yang sama, yaitu "membeli". Limba (2015) menjelaskan bahwa mo'ooli berasal dari

\footnotetext{
${ }^{1}$ Pada penelitian 2014 penulis menggunakan istilah ini dengan penulisan mo'ooli.
}

kata olio, artinya beli/tebus. Secara kontekstual ritual perladangan, mo'ooli artinya membeli atau menebus tanah yang akan dijadikan lokasi perladangan kepada pemiliknya 'nteiwonua'. Dalam artikel ini kata tersebut ditulis dengan meoli. Meoli adalah ritual adat Moronene yang digelar dengan tujuan meminta restu atas akan dilaksanakan sebuah hajat seperti membuka ladang, baik yangbersifat individu maupun komunal. Di dalam pelaksanaannya, ritual meoli tidak dapat dilepaskan dari penuturan mantra. Mantra dituturkan sebagai penyampaian pesan secara langsung dari penggelar ritual kepada sangia ntiwonиa yang diyakini memiliki kekuasaan atas alam semesta (Hastuti, 2015).

Pelafalan mantra dalam pelaksanaan sebuah ritual disesuaikan dengan semangat ritual itu sendiri. Ada yang diucapkan dengan suara lirih, lembut, dan nada menghiba, ada juga yang diucapkan dengan suara lantang, tegas, tetapi tetap santun dan beradab. Dalam ritual meoli, mantra diucapkan dengan suara lantang membahana dan menggema di segenap penjuru wilayah hutan. Mantra meoli sudah seperti itu diucapkan, tanpa diketahui kapan dan siapa yang memunculkan ritual ini pertama kali. Generasi demi generasi melaksanakan ritual meoli dengan model pelafalan mantra yang sama, sampai saat ini. Kesetiaan generasi muda melaksanakan ritual meoli menjadi dukungan bagi upaya pelestarian kekayaan sastra lisan Moronene sebagai bagian dari kekayaan budaya nusantara.

Danandjaja (1986) memasukkan mantra ke dalam kelas puisi rakyat. Mantra hadir bersama kepercayaan rakyat yang tentunya melekat dalam kehidupan sosial dan kemasyarakatan (Danandjaja, 1986, hlm. 46). Mantra meoli termasuk bentuk tuturan tertua yang dapat dikategorikan dalam genre puisi. Masyarakat tradisional Moronene sangat lekat dengan tuturan ini dalam kesehariannya karena mantra ini memiliki peran fungsional bagi masyarakatnya. 
Keindahan mantra meoli, sebagai pemenuhan fungsi estetika sastra, terletak pada susunan tuturan secara keseluruhan dan cara pengucapan yang khas. Susunan mantra meoli terdiri atas bait-bait dengan pengaturan rima dan repetisi di beberapa bagiannya. Struktur seperti ini tergolong puitis, mirip dengan puisi modern. Kepuitisan mantra meoli ini dalam pentasnya, didukung dengan pengucapan yang khas pula. Teknik pengaturan vokal dari pembue'a, orang yang mengucapkan mantra dalam pelaksanaan ritual meoli. Pentas dalam konteks ritual mengacu pada keadaan saat mantra dilafalkan dengan dikhidmati oleh peserta ritual. Pentas ritual disempurnakan dengan kehadiran perangkat syarat yang dibutuhkan, seperti sesajen atau pe'oli.

Penyusunan bahasa yang "berbeda" dari ucapan keseharian menandakan adanya permainan bahasa dalam mantra meoli sebagai sebuah ciri genre puisi. Keberbedaan ini muncul juga dalam pilihan kata yang selain mempertimbangkan makna juga memberi perhatian pada aspek bunyi, penekanan dengan adanya pengulangan, dan pengelompokan baris-baris kalimat membentuk bait. Kesemuanya itu menimbulkan nuansa puitis dalam pembacaan mantra meoli.

Etnopuitika mengacu pada kajian yang mengambil puisi sebagai objek kajian dan dikaitkan dengan aspek etnisitas. Secara garis besar, dapat dikatakan bahwa etnopuitika mengkaji kesenian atau sastra tradisional beserta aspek pendukungnya. Titik berat kajian ini terletak pada aspek intrinsik sebuah karya sastra yang dipentaskan (Rafiek, 2012). Adanya pembatasan yang terkandung dalam kata "pentas" mempersyaratkan adanya unsur pertunjukan dalam karya yang dijadikan objek kajian. Hal ini sejalan dengan batasan sastra lisan yang dikemukakan oleh Amir (2013). Unsur pentas dalam konteks mantra meoli terpenuhi dengan kehadirannya dalam sebuah ritual yang diikuti oleh peserta yang harus menyimak dengan sungguh-sungguh jalannya ritual.

Penelitian tentang tradisi sebuah masyarakat melalui pendekatan etnopuitika sudah banyak dilakukan, di antaranya adalah Sahril yang meneliti tentang tradisi "Syair Nyanyian Anak" dalam tradisi akikah. Syair ini sudah jarang dipentaskan dalam tradisi akikah pada masyarakat Melayu Sumatera Utara. Padahal, di dalamnya terkandung nilai-nilai didaktis yang dapat dijadikan bahan ajar serta pembentukan karakter anak-anak. Mengenai arah pendekatan penelitiannya, Sahril (2014) memberikan penjelasan bahwa etnopuitika diperkenalkan oleh Rothenberg melalui jurnal Alcheringa pada 1968. Dua hal yang menjadi fokus dalam etnoputika, yaitu aspek pentas sastra dan aspek makna. Kedua fokus dalam etnopuitika ini dapat dimanfaatan dalam menjawab permasalahan penelitian. Aspek pentas sastra mengkhususkan perhatian pada teks yang dipentaskan. Sementara itu, aspek makna langsung menuju pada fungsi teks tersebut, dengan segala elemen pengiringnya, bagi pemiliknya. Untuk itu, mutlak diperlukan pengetahuan mengenai budaya lokal sebagai modal untuk dapat menyelami teks dan konteksnya lebih dalam.

Penelitian terkait mantra melalui pendekatan etnopuitika dilakukan oleh Oktaviani yang mengangkat deskripsi mantra upacara Ngabati' pada upacara pertanian suku Dayak Kanayati. Dalam penelitian ini diperoleh simpulan bahwa dalam pelaksanannya, pentas mantra Ngabati harus memperhatikan penguasaan bahasa, sastra, busana, budaya lokal, makna mantra, dan seluruh detail pelaksanaan upacara (Oktaviani, 2015).

Lebih detail mengenai etnopuitika, dengan mengutip Sherzer dan Woodbury, Asfar (2016) menyimpulkan bahwa sebagai ancangan teortis etnopuitika bersifat fleksibel. Fokus yang dijadikan titik berat penelitian mungkin saja berbeda-beda, bergantung pada latar belakang keilmuan 
peneliti. Lebih lanjut, mengenai perkembangan etnopuitika, Asfar menyitir pendapat Jakobson bahwa muncul aspek pertalian sastra dan masyarakatnya. Masyarakat, khususnya masyarakat tradisional, kerap menitipkan nilai-nilai yang telah dilegitimasi secara adat di dalam sastranya. Terlebih, sastra lisan umumnya juga bernilai fungsional sehingga akrab dengan pemiliknya.

Mantra meoli hadir satu paket dalam kemasan pentas ritual yang bagi suku Moronene sebagai pemiliknya bersifat fungsional baik secara normatif maupun pragmatis. Corak tradisional yang masih demikian dekat dengan alam membuat orang Moronene masih berpegang pada warisan leluhur mereka. Jalinan yang telah berjalan sekian lama harus diupayakan tetap terpelihara harmonis. Orang-orang tua mereka menyediakan perangkat dalam upaya ini, termasuk pembiasaan melaksanakan ritual meoli. Ritual meoli dilakukan sebagai permohonan izin atau permintaan maaf atas pembukaan lahan hutan untuk bercocok tanam. Dari maksud ini, terlihat bahwa inti ritual ini adalah ekpresi kesantunan lokal yang telah diturunkan dari generasi ke generasi dalam bentuk ritual. Permasalahan yang diangkat dalam penelitian ini adalah bagaimana nilai kesantunan termuat dalam mantra meoli? Penggalian nilai kesantunan dalam mantra meoli dilakukan dengan mempertimbangkan makna serta budaya lokal di mana ritual meoli dilaksanakan.

\section{METODE PENELITIAN}

Penelitian ini dilakukan dengan menerapkan metode kualitatif. Pengumpulan data dilakukan dengan teknik observasi, wawancara, dan studi pustaka. Observasi langsung dilakukan saat pelaksanaan ritual meoli di Hukaea-Laeya, Kabupaten Bombana pada tahun 2014. Selain observasi untul memperoleh data berupa deskripsi pelaksanaan ritual dan teks mantra, dilakukan juga penelusuran pustaka untuk mendapatkan data pendukung seperti informasi budaya orang Moronene beserta dinamikanya.

Data utama berupa teks mantra meoli diperoleh dari rekaman pelaksanaan ritual meoli di Hukaea-Laeya. Rekaman data selanjutnya ditranskripsikan ke dalam bentuk tulisan (bahasa Moronene), selanjutnya diterjemahkan ke dalam bahasa Indonesia. Data dianalisis dengan mempertimbangkan relasi teks serta konteks yang bertalian dengan pertanyaan penelitian. Wawancara mengenai ritual dan budaya lokal dilakukan dengan informan Bapak Mansyur Lababa dan Bapak Aswarman, tokoh adat Moronene di Hukaea Laeya. Proses transkripsi mantra meoli dilakukan dengan bantuan Bapak Aswarman, sedangkan penerjemahan mantra meoli sepenuhnya dilakukan oleh Bapak Aswarman.

\section{PEMBAHASAN}

\section{Mantra dan Ritual Meoli}

Mantra meoli tersusun atas bait-bait dengan rima akhir yang mengentalkan nuansa puitis. Rima dan bait-bait yang hadir dengan kaidah puisi ini diperkuat dengan teknik pelantunan yang membahana di tepi hutan dan intonasi yang berirama. Suasana tepi hutan yang sunyi dengan desau angin dan suara serangga yang khas memunculkan efek syahdu dan takzim. Manusia seolah melekat dengan alam. $P e$ 'oli atau syarat ritual sudah disiapkan sebelumnya dan ditempatkan di atas sebuah rangka meja setinggi kurang lebih $120 \mathrm{~cm}$ yang terbuat dari kayu kecil sederhana. Warga yang hadir mengikuti jalannya ritual duduk diam mengkhidmati lantunan mantra.

Ritual meoli biasanya ditujukan untuk memohon izin atas pembukaan lahan untuk bercocok tanam. Akan tetapi, bisa juga dilakukan sebagai prmohonan maaf apabila pekerjaan membuka lahan sudah dilakukan tanpa didahului dengan ritual. Isi mantra merupakan permohonan izin dan restu dari 
roh-roh halus yang diyakini sebagai penghuni dan penguasa hutan di wilayah tobu Hukaea-Laeya. Selain memohon izin, mantra juga berisi permohonan agar wilayah tobu dan segenap penghuninya dilindungi dari marabahaya. Berikut ini bait-bait mantra meoli

(1)

Oooo ... asa orua otolu opaa

Oooo ... asa orua otolu opaa

Somba komiu sangia da tungkuo daa paraiho wonua hai Hukaea-Laeya

Naho ndoka

Naamiu kami memolu ontuu kami mebatangkaru

Leu la wa aku, hikuda munti hako pe oli ngku Cumio to matano oleo

Cumiu to puliano oleo

Cumiu to tangkeno

Cumiu to reteno

Saluwuluwumiu leu moala pe olingku

Kami sireako kameo peraa no mosao

Hai suerea ngkono limbo sungkano labanga

(2)

Oooo ... asa orua otolu opaa

Oooo ... asa orua otolu opaa

Somba komiu sangia da tungkuo daa paraiho

Cumio to matano oleo

Cumiu to puliano oleo

Cumiu to tangkeno

Cumiu to reteno

Saluwuluwumiu cumiu pera ro sangia

Pera eengkone kami leu mpoala peolingku

Kusie tekeke baakoako

Alako hai cumiu

Kami sireako komeo ano mo sao

Sirea tino wonua

Hai suerea ngkono limbo sungkano labanga

(3)

Oooo ... asa orua otolu opaa

Oooo ... asa orua otolu opaa

Somba komiu sangia da tungkuo daa paraiho

Saluwuluwumiu cumiu pera ro sangia

Die kaasi kusie Kusie tekeke baakoako lako

hai cumiu

Hi kuda mowango adati

Kami sireako komeo pera ha ano mo sao
(4)

Oooo ... asa orua otolu opaa

Somba komiu sangia da tungkuo daa paraiho

Wonua hai hukaea laeya

Naho, ndoka

Naamiu kami memolu ontuu kami

mebatangkaru

Leu la wa aku hi kuda munti hako pe'olingku

Cumio to matano oleo

Cumiu to puliano oleo

Cumiu to tangkeno

Cumiu to reteno

Saluwuluwumiu kami sireako akamio abalaa pera anumosao

Hai suerea ngkono limbo

Sungkano labanga

Artinya:

(1)

Oooo .... satu dua tiga empat

Oooo .... satu dua tiga empat

Mohon maaf wahai sangia yang menempati, yang membawahi tempat di Hukaea-Laeya

Iya katanya,

Supaya mudah melangkahkan kaki

Datanglah jemput aku, saya menurunkan pe oli-ku

Yang dari arah terbitnya matahari

Yang dari arah terbenamnya

Yang dari gunung

Yang di lembah

Kesemuanya datang mengambil peoli-ku

Singkirkanlah segala malapetaka yang akan merusak

Di tempat yang lain, yang sangat jauh

(2)

Oooo .... satu dua tiga empat

Oooo .... satu dua tiga empat

Mohon maaf wahai sangia yang menempati, yang membawahi

Yang dari arah terbitnya matahari

Yang dari arah terbenamnya

Yang dari gunung

Yang di lembah

Kesemuanya para penguasa

Kali ternama, kali yang datang mengambil pe'oli-ku

Supaya tidak mendapat teguran

Dari mereka

Supaya mereka bisa menyingkirkan hal-hal yang buruk 
Celakanya kampung

Di tempat yang sangat jauh

(3)

Oooo .... satu dua tiga empat

Oooo .... satu dua tiga empat

Mohon maaf wahai sangia yang menempati yang membawahi

Ini kasihan, jangan saya mendapat teguran dari kita

sementara saya membangun adat

singkirkan segala mala petaka

(4)

Oooo .... satu dua tiga empat

Oooo .... satu dua tiga empat

Mohon maaf wahai sangia yang menempati,

yang membawahi daerah Hukaea-Laeya

Iya, katanya

Ini mungkin, kalian memudahkan langkah

Melemaskan lutut (untuk memudahkan

melangkah)

Datang menjemputku

Sementara saya menurunkan peoli-ku

Yang dari arah terbitnya matahari

Yang dari arah terbenamnya

Yang dari gunung

Yang di lembah

Kesemuanya singkirkanlah marabahaya

malapetaka

Yang jelek

Celakanya kampung

Di tempat yang sangat jauh

Membicarakan mantra meoli tidak dapat dipisahkan dari membicarakan ritual meoli karena keduanya hadir satu paket dalam satu pentas. Selain mantra, dalam pelaksanaan ritual meoli juga diperlukan beberapa barang/benda persembahan sebagai sajen. Sajen ini oleh orang Moronene disebut pe'oli. Pe'oli yang disiapkan sebelum pelaksanaan ritual meoli di Hukaea-Laeya, di mana peneliti menjadi bagian dalam ritual tersebut, berupa sepasang pakaian laki-laki dan sepasang pakaian perempuan, daun sirih 'bite', buah pinang 'wua', kapur sirih 'ngapi', tembakau 'ahu', dan lintingan kulit jagung 'kulimpuhu'. Pe'oli disusun di dalam sebuah be'u, wadah kotak terbuat dari anyaman daun pandan. $B e^{\prime} u$ yang digunakan dalam dilapisi kain merah yang dijahit pada keliling lingkaran be'u.

Ritual diawali dengan

mempersiapkan tempat, biasanya di pinggiran hutan tidak jauh dari mulut gua tempat makam leluhur sebagai wilayah yang dikeramatkan. Setelah tempat siap, dilakukanlah ritual meoli dipimpin oleh seorang pembawa adat yang disebut tumpuroo atau pembua'e. Dalam Limba (2016) disebutkan bahwa dalam kapasitasnya sebagai pembaca mantra, pembawa adat disebut pembua'e.

Sebelum membacakan mantra, pembua'e mempersiapkan dirinya sebaik mungkin karena pada hakikatnya apa yang akan dilakukan adalah sebuah komunikasi dengan makhluk gaib yang dihormati. Lalu, dalam posisi berlutut dan kepala menunduk pembua'e mengangkat be'u berisi pe'oli. Dengan kepala masih menunduk, pembua'e berdiri dan meletakkan be'u di atas rangka kayu yang telah dibuat sebelumnya. Lalu mulailah dia melafalkan mantra meoli dalam posisi berdiri dan kedua tangan dilipat di depan dada.

Ritual berlangsung dengan khidmat. Peserta ritual mendengarkan mantra yang dilafalkan dengan saksama. Selain itu, mereka juga memperhatikan jenis serangga yang beterbangan dan hinggap di sekitar tempat ritual. Sebagai bentuk komunikasi, ritual meoli sudah memiliki ketentuan tersendiri. Alam dijadikan tanda yang bermakna. Dalam konteks ritual meoli sebagai komunikasi, kehadiran kupu-kupu, lalat, dan capung menjadi pertanda bahwa permintaan mereka dikabulkan atau diizinkan. Sementara itu, jika jenis tawon yang muncul, baik terbang maupun hinggap di tempat ritual, menandakan permohonan mereka ditolak oleh para sangia. Pertandapertanda alam ini yang harus diperhatikan selama pembua'e melafalkan mantra.

\section{Etnopuitika Mantra Meoli}

Dua baris pertama yang muncul juga di awal bait-bait selanjutnya Oоoо ... asa, orua, otolu, opaa [Oooo .... satu dua tiga 
empat] memuat kata seruan yang ditujukan pada para sangia penghuni dan penguasa alam dan bilangan filosofis orang Moronene $(1,2,3,4)$ yang biasa disebut sulapa opaa. Pembue'a membuka pelafalan mantra dengan suara tinggi dan berwibawa. Sulapa opaa dianggap sebagai perlambang empat elemen penyusun kehidupan, yaitu air, tanah, angin, dan api. Setiap elemen memiliki sangia masing-masing, yaitu Sangia Olaro penguasa alam air, Sangia Tumondete panguasa alam tanah, Sangia Lamoa penguasa alam angin, dan Sangia Mponga'e penguasa alam api. Mengapa seruan ini perlu diucapkan? Pada dasarnya ritual meoli adalah sebuah proses komunikasi antara pelaku ritual sebagai penyampai pesan dan sangia sebagai target penerima pesan. Sebagai pihak yang berniat menyampaikan pesan, pelaku ritual harus memanggil target terlebih dahulu, maka diawalilah mantra dengan kata seruan untuk menarik perhatian, tetapi tetap mengutamakan kesantunan dan kerendahhatian.

Baris Somba komiu sangia da tungkuo daa paraiho wonua hai HukaeaLaeya [Mohon maaf wahai sangia yang menempati, yang membawahi tempat di Hukaea-Laeya] bersifat tuturan langsung dengan struktur kalimat yang lengkap. Permohonan maaf sebelum mengutarakan maksud dan keperluan ini merupakan ciri adab dan sopan santun dalam berkomunikasi. Pemilihan sebutan bagi para sangia sebagai yang membawahi/menguasai Hukaea-Laeya pun menunjukkan bahwa pelaku ritual memosisikan para sangia itu sebagai pihak yang superior di wilayah Hukaea-Laeya.

Baris Naho ndoka [Iya katanya] diucapkan oleh pembue'a sebagai harapan bahwa itulah yang diucapkan oleh para sangia sebagai jawaban atas seruan atau panggilan pada baris sebelumnya. Jawaban yang seolah-olah ucapan para sangia ini menunjukkan besarnya harapan para pelaku ritual bahwa panggilan mereka setidaknya disahut sebagai tanggapan awal yang baik.
Cukup menarik dicermati ucapan yang seolah-olah datang dari para sangia dan diucapkan dengan sadar oleh pembue'a ini, yaitu keyakinan yang kuat dari warga pelaku ritual bahwa para sangia akan selalu hadir menyertai kehidupan di HukaeaLaeya. Orang Moronene, khusunya di Hukaea-Laeya, yang melakukan ritual meoli sangat percaya bahwa para sangia yang tidak lain adalah roh leluhur tidak akan mengabaikan generasi penerusnya.

Orang Moronene yakin mereka tidak sendiri dalam mengelola sumber daya yang telah disediakan oleh alam ini. ada kekuatan yang tidak terlihat selalu bisa diandalkan untuk dimintai pertolongan. Kebergantungan ini menunjukkan dua hal, pertama adalah bahwa orang Moronene memiliki keterikatan emosional yang tinggi dengan leluhurnya. Kedua, orang Moronene meyakini restu orang-orang tua, yang direpresentasikan oleh para sangia, menjadi salah satu faktor penentu keberhasilan usaha mereka.

Baris Naamiu kami memolu ontuu kami mebatangkaru. Leu la wa aku, hikuda munti hako pe oli ngku [Supaya mudah melangkahkan kaki. Datanglah jemput aku, saya menurunkan pe oli-ku] menunjukkan bahasa bernuansa sastra dengan adanya pembalikan struktur. Sebagai struktur semantis apabila disusun secara paralel, kedua kalimat ini bermakna harapan agar pe'oli yang dipersembahkan dapat diterima. Diterimanya pe'oli akan memudahkan langkah pekerjaan selanjutnya.

Baris Cumio to matano oleo; Cumiu to puliano oleo; Cumiu to tangkeno; Cumiu to reteno; Saluwuluwumiu leu moala pe'olingku [Yang dari arah terbitnya matahari; Yang dari arah terbenamnya; Yang dari gunung; Yang di lembah; Kesemuanya datang mengambil peoli-ku] merupakan lima baris yang mewakii satu kesatuan makna. Repetisi kata cumiu to di awal baris memunculkan estetika yang membuat mantra meoli ini bernilai sastra. Secara gramatikal, subjek kalimat 
terepresentasikan dalam empat baris pertama. Barisan subjek ini diikuti dengan kalimat lengkap yang subjeknya merupakan pengulangan kembali atas pengulanganpengulangan yang terdapat pada empat baris sebelumnya. Pengulangan ganda ini menunjukkan pentingnya posisi para sangia dalam ritual meoli. Para sangia adalah subjek yang diharapkan sudi mengambil atau menerima pe'oli yang dipersembahkan. Bisa jadi penekanan ini menunjukkan pemosisian yang begitu tinggi bagi para sangia. Pentingnya para sangia melebihi pentingnya isi permintaan atau permohonan izin yang disampaikan dalam ritual.

Baris Kami sireako kameo peraa no mosao; Hai suerea ngkono limbo sungkano labanga; Kami sireako kameo peraa no mosao; Hai suerea ngkono limbo sungkano labanga [Singkirkanlah segala malapetaka yang akan merusak; Di tempat yang lain, yang sangat jauh] memuat permintaan tersurat, yaitu setelah pe'oli diterima agar para sangia berkenan membuang jauh-jauh petaka atau kesialan dan segala malapetaka. Apakah baris ini menunjukkan ketidakpedulian orang Moronene terhadap tempat di luar wilayah mereka? Tampaknya, baris ini menunjukkan juga konsep berpikir bahwa tempat yang sangat jauh itu adalah tempat yangtidak pernah muncul dalam bayangan mereka sebelumnya. Bisa jadi di "tempat yang sangat jauh" yang dimaksud adalah tempat di mana tidak ada makhluk hidup yang merasa terganggu dengan buangan malapetaka. Pak Aswarman, sebagai pembua'e dalam ritual sekaligus informan bagi penelitian ini, mengatakan bahwa tempat yang sangat jauh itu ya jauh, tidak pernah terpikirkan tempat itu ada di mana.

Secara umum bait kedua mengulang kembali bait pertama dengan perbedaan pada beberapa baris di bagian akhir bait, Kusie tekeke baakoako; Alako hai cumiu; Kami sireako komeo ano mo sao; Sirea tino wonua; Hai suerea ngkono limbo sungkano labanga [Supaya tidak mendapat teguran;
Dari mereka; Supaya mereka bisa menyingkirkan hal-hal yang buruk; Celakanya kampung; Di tempat yang jauh]. Seperti anak kecil yang khawatir dimarahi oleh orang tuanya, orang Moronene merasa perlu "membujuk" para sangia dengan persembahan pe'oli dan pelaksanaan ritual.

Empat baris terakhir bait ketiga Somba komiu sangia da tungkuo daa paraiho; Saluwuluwumiu cumiu pera ro sangia; Die kaasi kusie Kusie tekeke baakoako lako hai cumiu; Hi kuda mowango adati; Kami sireako komeo pera ha ano mo sao [Ini kasihan, jangan saya mendapat teguran; dari kita; sementara saya membangun adat; singkirkan segala mala petaka] memuat dua hal yang menarik. Masih berupa permohonan agar dihindarkan dari malapetaka dan kesialan, tetapi pada bait ketiga ini kalimat mantra memohon lebih sangat dengan penggunaan kata kaasi. Warga melalui pembua'e minta dikasihani oleh para sangia agar tidak ditimpa malapetaka.

Masih pada bait ketiga, terungkap adanya hubungan timbal balik antara para sangia dan orang Moronene sebagai pelaku ritual meoli. Pelaku ritual meminta perlindungan dari para sangia agar mereka aman dan damai dalam membangun adat. Adat merupakan warisan yang diperoleh secara turun temurun, yang apabila dirunut, bisa jadi yang mencetuskan adat pertama kali adalah mereka yang diyakini menjadi sangia. Penyebutan membangun dan merawat adat ini menjadi bahan penawaran selain pe'oli. Terbaca harmoni antargenerasi. Para sangia sebagai generasi awal berkuasa membeikan berkah dan keamanan kepada generasi yang masih hidup dan bersedia menjaga peninggalan mereka yang berharga, yaitu adat.

Bait keempat secara keseluruhan adalah pengulangan dari bait-bait sebelumnya. Pengulangan demi pengulangan dalam mantra meoli selain menunjukkan nilai estetis sastrawi juga menunjukkan pentingnya komunikasi ini dalam adat. 
Bagian yang mendapat penekanan dalam mantra meoli adalah para sangia sebagai target penerima pesan dan harapan agar terhindar dari malapetaka. Dalam bahasa yang lebih sederhana, warga meminta izin untuk membuka lahan dan mereka mengharapkan para sangia tidak marah karena pembukaan lahan itu. Sejumlah pe'oli dipersembahkan sebagai syarat ritual permohonan ini.

\section{Nilai Kesantunan dalam Mantra Meoli}

Ritual meoli dilaksanakan sebagai permintaan izin membuka lahan atau permintaan maaf karena membuka lahan tanpa didahului syarat adat. Dari tujuan ini diketahui betapa orang Moronene sebagai pemilik ritual me'oli mengedepankan sopan santun dalam pengelolaan sumber daya alam. Nilai kesantunan termuat dalam mantra meoli, baik dalam pilihan kata maupun strukturnya.

Setiap bait diawali dengan seruan dan penyebutan bilangan sulapa opaa. Sulapa opaa sebagai representasi adat yang diwariskan oleh leluhur (para sangia) ditempatkan di bagian awal mantra. Hal ini menjadi pertanda bahwa peserta ritual menjunjung adat sebagai sesuatu yang diutamakan. Pernyataan ini menjadi salah satu nilai kesantunan dalam mantra meoli.

Setelah pernyataan pengutamaan adat, dalam setiap bait mantra diungkapkan permohonan maaf apabila pelaksanaan ritual itu terasa mengusik ketenangan para sangia. Permohonan maaf sebelum mengutarakan maksud ini dengan jelas dapat dikatakan bernilai kesantunan. Bahkan, dalam percakapan sehari-hari pada masa sekarang pun nilai kesantunan ditunjukkan dengan permintaan maaf ketika hendak membuka pembicaraan. Permintaan maaf bukan karena penyampai pesan bersalah, tetapi lebih karena rasa khawatir bahwa target penerima pesan merasa terganggu atas proses komunikasi, setidaknya menyita waktu dan perhatiannya.
Penyebutan target penerima pesan (para sangia) dengan lengkap menunjukkan kesantunan dalam menghargai semua sangia tanpa kecuali. Teknik pengulangan dalam penyebutan target penerima pesan ini berulang pada bait pertama, kedua, dan keempat dengan lafal sebagai berikut

\section{Cumio to matano oleo \\ Cumiu to puliano oleo \\ Cumiu to tangkeno \\ Cumiu to reteno}

Artinya:

Yang dari arah terbitnya matahari

Yang dari arah terbenamnya

Yang dari gunung

Yang di lembah

Selain penekanan terhadap aspek semantis, teknik repetisi ini juga memunculkan estetika dalam pelafalan mantra. Pengungkapan yang indah ini mendukung nilai kesantunan yang termuat secara maknawi di seluruh untaian kalimat mantra meoli.

Bagian awal setiap bait mantra meoli diikuti dengan bagian pengutaraan maksud. Pertama, harapan agar para sangia berkenan menerima pe'oli yang dipersembahkan. Kedua, harapan agar para sangia melindungi Hukaea-Laeya dan penghuninya dari malapetaka. Harapan ini diutarakan dalam ekspresi yang santun. Kata kaasi dalam percakapan biasa digunakan untuk ekspresi mengharapkan belas kasihan. Kata ini digunakan dalam bait ketiga, yaitu harapan agar tidak mendapat teguran. Teguran dari para sangia biasanya berupa bencana atau malapetaka. Lebih jauh, di akhir bait (pertama, kedua, dan keempat) dipanjatkan juga harapan agar malapetaka disingkirkan ke tempat yang (sangat) jauh. Tempat yang sangat jauh ini menyiratkan lokasi yang tidakbersentuhan dengan manusia atau makhluk hidup lain yang mungkin saja akan merasa menderita jika ditimpa buangan malapetaka. Nilai 
kesantunan pada bagian ini juga menunjukkan ketidakegoisan pelaku ritual.

\section{PENUTUP}

Nilai kesantunan dalam mantra meoli mewujud dalam berbagai aspeknya. SIkap tubuh dan intonasi saat pengucapan mantra menunjukkan sikap merendah. Selain itu, penyediaan pe'oli menjadi pertanda kesediaan para pelaku upacara memenuhi persyaratan adat yang sudah ditetapkan oleh leluhur mereka. Dalam mantra meoli secara tekstual, nilai kesantunan terbaca dari penempatan prioritas dalam bait-baitnya. Yang pertama dan diutamakan adalah penjunjungan adat. Pengutamaan ini menunjukkan penghormatan dari generasi sekarang terhadap apa yang telah diwariskan oleh pendahulunya. Kedua, permohonan maaf dengan menyebutkan seluruh sangia yang ada dalam sistem kepercayaan suku Moronene di HukaeaLaeya. Penyebutan ini menunjukkan penghormatan yang tertuju kepada semua dewa dan kekuatan gaib di alam semesta. Dewa dan kekuatan gaib ini merupakan representasi dari leluhur yang telah menggariskan adat dalam tatanan kehidupan suku Moronene di HukaeaLaeya. Ketiga, rangkaian ungkapan penghormatan itu barulah dipungkasi dengan pengutaraan maksud, harapan, dan permintaan sebagai inti pesan dari mantra meoli. Skala prioritas dalam mantra sebagai bentuk komunikasi didukung dengan cara pengungkapan yang indah melalui teknik repetisi dan teknik vokal yang lantang membahana, sangat padu dengan suasana tepi hutan sebagai latar pentas/tempat ritual.

\section{DAFTAR PUSTAKA}

Amir, A. (2013). Sastra Lisan Indonesia. Yogyakarta: Penerbit Andi.

Asfar, D. A. (2016). Kearifan Lokal dan Ciri Kebahasaan Teks Naratif Masyarakat Iban. Litera, 15(2), 366-
378.

Danandjaja, J. (1986). Folklor Indonesia: Ilmu Gosip, Dongeng, dan Lain-lain. Jakarta: PT Pustaka Grafitipers.

Hastuti, H. B. P. (2015). Ritual Adat Mo'ooli Suku Moronene. Kendari: Kantor Bahasa Provinsi Sulawesi Tenggara.

Hastuti, H. B. P., Pranawengtyas, D. R., \& Nitayadnya, I. W. (2016). Khazanah Sastra Daerah di Sulawesi Bagian Selatan. (M. Yamaguchi, Ed.). Kyoto: Hokuto Publishing.

Limba, R. S. (2016). Kearifan Lokal Masyarakat Adat Moronene: Pola Konservasi Hutan dalam Sistem Pertanian Ladang (Studi Kasus di Kampung Huka'ea-Laea, Desa WatuWatu Kecamatan Lantari Jaya Kabupaten Bombana) (Disertasi). Program Pascasarjana Universitas Haluoleo, Kendari.

Limba, R. S., Melamba, B., \& Ferdinan, A. (2015). Sejarah Peradaban Moronene. Yogyakarta: Penerbit Lukita.

Muis, E. W. (2010). Tumbuhan moronene: Relasi antara budaya dan falsafah hidup masyarakat Moronene (Tesis). Program Pascasasrjana Universitas Gadjah Mada, Yogyakarta.

Oktaviani, U. D. (2015). Mantra Upacara Ngabati' pada Upacara Pertanian Suku Dayak Kanayatn di Dusun Pakbuis Desa Banying Kecamatan Sengah Temila Kabuoaten Landak Kalimantan Barat (Kajian etnopuitika). VOX Edukasi: Jurnal Ilmiah Ilmu Pendidikan, 6(2). Diakses melalui jurnal.stikeppersada.ac.id

Rafiek, M. (2012). Pementasan Madihin Banjar: Kajian Etnopuitika. Dalam Teori sastra: Kajian teori dan praktik. Bandung: PT Refika Aditama.

Sahril. (2014). Tradisi Akikah Masyarakat Melayu Pentas Sastra Lokal "Syair 
Nyanyian Anak." Jentera: Jurnal

Kajian Sastra, 3(1), 59-71.

Sumber wawancara:

Aswarman, pembua'e pada ritual meoli

Drs. Mansyur Lababa, pemuka adat Moronene di Hukaea-Laeya.

Jumrad Raunde, Ketua Dewan AMAN

(Aliansi Masyarakat Adat Nusantara)

Kabupaten Bombana. 